\title{
Common Injuries of Collegiate Tennis Players
}

\author{
Christian Wisdom Magtajas Valleser ${ }^{1}$ and Ken Ewing L. Narvasa ${ }^{1}$
}

Affiliations: 'University of the Philippines Diliman, Department of Sports Science, College of Human Kinetics, Quezon City, Philippines

Correspondence: Christian Wisdom Magtajas Valleser, University of the Philippines Diliman, Department of Sports Science, College of Human Kinetics, Don Mariano Marcos Avenue, Diliman, Quezon City, Philippines, 1101. E-mail: cmvalleser@up.edu.ph

ABSTRACT The purpose of this study is to determine the common injuries of Filipino collegiate tennis players; 110 varsity tennis players with a mean of 20 years old $(S D \pm 1.7)$ with an average playing experience of 12 years participated in the study. There was a 100\% occurrence of at least one injury with an average rate of 5.98 injuries per person. The authors observed that the most commonly injured anatomical region is the lower extremity; ankles were recorded as the most commonly injured part. Other commonly injured areas included the shoulders and lower back. Furthermore, the most common injury type is tendinitis, sprains, and strains. The recorded injuries were mostly associated with overuse injuries, and the findings were similar to those of most other studies on tennis injuries. A larger sample size may provide more conclusive findings on tennis injuries, particularly in different levels of competition, such as recreational or professional athletes.

KEY WORDS Injuries, Collegiate, Tennis, Student-athletes.

(0)

$@ M J S S M o n t e n e g r o$

COMMON INJURIES OF COLLEGIATE TENNIS

$\mathrm{http}: / / \mathrm{mjssm} . \mathrm{me} /$ ?sekcija=article\&artid=141

\section{Introduction}

It is widely accepted that while engaging in sports and physical activities reduces the risk of certain diseases, it also entails a noticeable risk of injury among all levels of participation (Bahr \& Krosshaug, 2005). Although there is no universally accepted definition, this study defines sports injury as a physical condition incurred as a result of sport participation, which requires medical attention and restriction of participation or performance (Hootman, Dick \& Agel, 2007). The general objective of this study is to identify the common injuries incurred by collegiate tennis players using student athletes from participant schools of the University Athletic Association of the Philippines (UAAP). Specifically, this research aims to identify the common type of injuries and most commonly injured anatomical regions.

Tennis is a sport widely participated in by the more than 200 countries affiliated with the International Tennis Federation. Along with its popularity are the various national and international tournaments organized throughout the year, many of which feature large prizes (Pluim, Staal, Windler \& Jayanthi, 2006). There is increasing research on the epidemiology of tennis and other sport injuries, which further promotes the awareness of injury tendencies and the development of prevention strategies (Rechel, Yard \& Comstock, 2008; Hootman et al., 2007).

On the international level, tennis is featured in the Olympics and most notably in major tournaments, such as the Australian Open, Wimbledon Championships, French Open, and US Open. In the Philippines, there are various professional and amateur tennis tournaments; most notably, on the amateur level, the UAAP typically features the best collegiate tennis players in the country. Collegiate players in the UAAP normally take up the sport at a young age, typically no later than ten years old. The risk of early introduction and regular participation in sports is that players starting young could acquire chronic injuries, especially when trained with techniques that are not compatible with what their bodies can tolerate (Reid \& Schneiker, 2007). Furthermore, long-term sport participation can cause chronic and acute injuries in the developing bodies of child- and adolescent-aged athletes (DiFiori et al., 2014).

Safran, Zachazewski, Benedetti, Bartolozzi III and Mendelbaum (1999) reported that many athletes have

Accepted after revision: March 292017 | First published online: September 012017

(c) 2017 by the author(s). License MSA, Podgorica, Montenegro. This article is an open access article distributed under the terms and conditions of the Creative Commons Attribution (CC BY).

Conflict of interest: None declared. 
claimed that they played or competed through these discomforts. They further noted that low back pain was common in elite junior players. Hellstrom, Jacobsson, Sward and Peterson (1990) also made this observation in elite adult players. Lower-back pain from tennis comes from a wide variety of sources but is mainly due to high demands placed on the lower back and trunk combined with low flexibility resulting in frequent overusetype injuries. Kibler and Safran (2005) observed that ankle sprains were the most common microtrauma injury in tennis due to the frequent running, pivoting, sudden stopping, acceleration, jumping, and lunging movements in tennis play. Furthermore, lateral epicondylitis (tennis elbow) and medial epicondylitis chronic repetitive motion through firm gripping of the handle of the racket and impact of the ball were common. Generally, hand and wrist complaints are observed, specifically tendinitis. It is often common to have a two-handed backhand stroke in which the non-dominant wrist receives stress through overuse during the backswing phase of the stroke. Strains in the adductor muscles and hamstring are also common, primarily due to sudden changes in direction or slipping on clay courts resulting in splits.

It was also reported by Ireland and Hutchinson (1995) that stress fractures of the ulna of the non-dominant forearm, as well as distal radius and ulna fractures of the dominant wrist, were reported in players with forearm and wrist pain. Renstrom (1995) indicated that 19\% of all tennis-related injuries are knee injuries, $70 \%$ being acute and $30 \%$ overuse.

Most sports injuries, tennis included, occur in the lower extremities particularly the knee and ankles (Pluim et al. 2006; Hootman et al. 2007; Rechel et al., 2008; Abrams, Safran \& Renstrom, 2012) while injuries in the trunk were the least common (Rechel et al., 2008; Chard \& Lachman, 1987). In the study by Hjelm, Werner, and Renstrom (2010) on the injury profile of junior tennis players, the lumbar spine was the most commonly injured body part. In contrast, Pluim et al. (2006) stated that the most commonly injured anatomical region is the upper extremities followed by the lower extremities and the least injured part was the trunk. In the summary by Kibler and Safran (2005), the most injured region is the lower extremities accounting for 39-59\% of reported injuries followed by the upper extremities with $20-45 \%$, and lastly the central core with $11-30 \%$ of the total injuries reported. Specifically, the ankles and the thighs showed the highest frequency in the lower extremities, the shoulders and elbows in the upper extremities, and the lower back in the central core.

Concerning practice and tournament injury rates, Hootman et al. (2007) observed that in-season tournaments produced the highest injury rates followed by pre-season practices and in-season practice among student-athletes. Meanwhile, post-season practice accounted for the lowest injury rates. Rechel et al. (2008) also observed that as the level of competition increases so do injury rates and that most injuries occur in competition as opposed to in practice. A variety of reasons that may explain why injury rates are higher during preseason practice than during in-season or post-season practice have been suggested such as coming to pre-season practice poorly conditioned, the duration of pre-season practices being longer than other sport seasons, less-skilled athletes trying to improve technique and becoming injured, and pre-season competitiveness in which players battle for starting positions.

\section{Methods}

This study is descriptive research design to identify the common injuries of collegiate tennis players, specifically, the most common types of injury and the anatomical regions at risk.

\section{Subjects}

The criteria for the selection of research participants were as follows: (1) a current varsity player of a UAAP school for at least one year and (2) must have played in at least one UAAP season; 110 (60 male, 50 female) collegiate student-athletes $\left(M_{\text {age }} 20 \pm 1.7\right.$ yrs.) representing $100 \%$ of all UAAP tennis players in a specific season participated in the study. The subjects had an average playing experience of $12(\mathrm{SD} \pm 2.4)$ years.

\section{Procedure}

Data were collected through a survey questionnaire and guided interview using a sports injury questionnaire adapted from Duco (2005) and Reyes (2005). The injury inventory is divided into 20 anatomical regions and identifies nine (9) types of injuries. Certain additions were also gathered to meet the specific objectives of this study, including (1) the message in the project information box, (2) details in the demographic information (3) addition of other types of injuries, (4) the definition of specific types of injury, (5) a more detailed enumeration of musculoskeletal regions and (6) a specified area for other injuries that may not have been covered in the questionnaire such as other anatomical areas or multiple injuries in the same anatomical region. The survey questionnaire has been reviewed by a medical professional in a sports physical therapy unit and verified to meet the specific objectives of the study.

Responses were gathered at the respondents' playing venue. Letters of request were first sent to the coaches, after which, upon being given permission to have access to their players, informed consents were handed out to the players. A brief overview of the objectives and procedure was given to all participants prior to the data collection. 
distribution tables. Graphs are also used to display the findings and provide an overview of common injury trends in collegiate tennis players.

Results

A total of 658 injuries were reported. There was a 100\% incidence of at least one injury among the athletes with an average of close to 6 injuries per person. The data showed that the following are the most frequently reported injury types: tendinitis (39\%), sprains (32\%) and strains (22\%). All other injuries were reported at an occurrence of $4 \%$ or lesser. Table 1 below summarizes the frequency and percentage distribution of reported injuries.

\begin{tabular}{lll}
\multicolumn{2}{c}{ TABLE 1 Frequency and percentage distribution of type of injury. } \\
Type of injury & Frequency & $\%$ \\
\hline Tendinitis & 254 & 39 \\
Sprain & 211 & 32 \\
Strain & 148 & 22 \\
Inflammation & 24 & 4 \\
Abrasion & 12 & 2 \\
Stress Fracture & 6 & $<1$ \\
Dislocation & 2 & $<1$ \\
Fracture & 1 & $<1$ \\
\hline TOTAL & 658 & $100 \%$ \\
\hline
\end{tabular}

Of all reported injuries, the most common are tendinitis; of these, most were in the shoulders, elbows, knees and wrist $(30 \%, 27 \%, 20 \%$, and $9 \%$ of all reported injuries, respectively). Below, Table 2 presents the percentage distribution of the occurrence of tendinitis.

\section{TABLE 2 Percentage distribution of the occurrence of tendinitis.}

\begin{tabular}{ll} 
Anatomical region & $\%$ \\
\hline Shoulders & 30 \\
Elbows & 27 \\
Knees & 20 \\
Wrists & 14 \\
Others & 9 \\
\hline TOTAL & $100 \%$ \\
\hline
\end{tabular}

The second most common injury were sprains, accounting for $32 \%$ of all reported injuries. Sprains were mostly reported in the ankles (94\%) and some on the wrists (5\%). The percentage distribution of the occurrence of sprains can be seen below in Table 3 .

TABLE 3 Percentage distribution of the occurrence of sprains.

\begin{tabular}{ll} 
Anatomical region & $\%$ \\
\hline Ankles & 94 \\
Wrists & 5 \\
Others & 1 \\
\hline TOTAL & $100 \%$ \\
\hline
\end{tabular}

The third most common injury, representing $22 \%$ of all reported injuries, were strains. Strains were most likely to be in the lower back (45\%) followed by the shoulders (19\%) and thighs (17\%). Table 4 below illustrates the reported occurrence of strains.

\begin{tabular}{ll} 
TABLE 4 Percentage distribution of the occurrence of strains. \\
Anatomical region & $\%$ \\
\hline Lower back & 45 \\
Shoulders & 19 \\
Thighs & 17 \\
Others & 19 \\
\hline TOTAL & $100 \%$ \\
\hline
\end{tabular}




\section{Anatomical Region}

Regarding the anatomical regions at risk, injuries commonly occurred in the ankles (30\%), shoulders (16\%), lower back (12\%), knees (11\%) and elbows (10\%). All other injury sites were reported to be injured at a rate of seven percent or less. Table 5 below summarizes the frequency and percentage distribution of injuries by anatomical region.

TABLE 5 Frequency and percentage distribution of injuries by anatomical region.

\begin{tabular}{lll} 
Anatomical region & Frequency & $\%$ \\
\hline Ankles & 198 & 30 \\
Shoulders & 106 & 16 \\
Lower back & 82 & 12 \\
Knees & 71 & 11 \\
Elbows & 68 & 10 \\
Wrists & 45 & 7 \\
Thighs & 26 & 4 \\
Lower leg & 17 & 3 \\
Forearms & 12 & 2 \\
Arms & 7 & 1 \\
Upper back & 6 & 1 \\
Feet & 6 & $<1 \%$ \\
Groin & 6 & $<1 \%$ \\
Head & 4 & $<1 \%$ \\
Hands & 2 & $<1 \%$ \\
Abdomen & 2 & $<1 \%$ \\
\hline TOTAL & 658 & $100 \%$ \\
\hline
\end{tabular}

As the most injured anatomical region, all reported injuries in the ankles were sprains, suggesting the vulnerability of the ankles to sprains. As such, all 198 incidences were ankle sprains. In contrast, injuries in the shoulders were mostly in the form of tendinitis, observed to be accountable for $70 \%$ of all injuries in the shoulders, followed by strains (26\%). Below, Table 6 summarizes the reported shoulder injuries.

\begin{tabular}{ll}
\multicolumn{2}{l}{ TABLE 6 Percentage distribution of shoulder injuries. } \\
Injury & $\%$ \\
\hline Tendinitis & 70 \\
Strain & 26 \\
Dislocation & 2 \\
Others & 2 \\
\hline TOTAL & 100 \\
\hline
\end{tabular}

The lower back was reported to be the third most frequently injured anatomical region. Of all injuries in the lower back, the clear majority were strains $(86 \%)$, suggesting the susceptibility of the lower back to strains among tennis players, while the rest were inflammation (14\%) or swelling characterized by tenderness and pain which may or may not be related to strains.

Meanwhile, the fourth most injured region were the knees, mostly in the form of tendinitis (69\%) with a few strains (18\%) and abrasions (11\%). Table 7 below shows the summary of reported knee injuries.

\begin{tabular}{ll} 
TABLE 7 Percentage distribution of knee injuries. & \\
Injury & $\%$ \\
\hline Tendinitis & 69 \\
Strain & 18 \\
Abrasion & 11 \\
Sprain & 2 \\
\hline TOTAL & 100 \\
\hline
\end{tabular}

The elbows were the location for $10 \%$ of all injuries, the fifth most injured anatomical region. All injuries in the elbow were reported to be tendinitis, most probably lateral epicondylitis or "tennis elbow". All other 
anatomical regions were reported to be injured less frequently and represent a smaller proportion of all injured anatomical regions.

\section{Discussion}

Tendinitis, sprains, and strains were clearly the most common types of injury, as observed in the data. This observation is similar to that of Kibler and Safran (2005), and they postulate that these are mostly microtrauma-related overuse injuries. It may be inferred that most injuries recorded in this study were due to overuse rather than acutely incurred injuries. The findings are also consistent with the conclusions of Lanese, Strauss, Leizman, and Rotondi (1990) and Rechel et al. (2008).

Tennis injuries may occur in many musculoskeletal areas but will most likely be in the ankles, shoulders and lower back. Ankle sprains are perhaps the most common injury in tennis as well as in many sports. In contrast, tendinitis was mostly found in the elbow or shoulders, presumably due to repeated stress, which gives credence to the previous speculation that most injuries will be caused by chronic overuse. These findings were also previously observed by numerous studies (Kibler \& Safran, 2005); Pluim et al., 2006; Hootman et al., 2007; Rechel et al., 2008).

Tennis injury studies mostly concur with each other, which suggests the proclivity of tennis to certain injuries. According to the findings of this study, overuse injuries in the form of tendinitis, sprains, and strains were found to be most common especially in the upper extremities. Overall, however, the upper and lower extremities seem to be most susceptible to injuries, primarily due to overuse and may be chronic if not properly addressed.

To further minimize the risk of injury, strength and conditioning programs are recommended to focus on strengthening the upper and lower extremities, specifically the ankles and shoulders. As injuries in tennis may be unavoidable, coaches and team physicians are advised to be prepared for recurring injuries in the upper and lower extremities. Despite the relatively high number of injuries reported, the fact that all these players still have active collegiate careers suggests that returning to play is still very possible. As such, tennis can be safe with an inherent risk of injury, just like many other sports.

\section{REFERENCES}

Abrams, G., Safran, M.R. \& Renstorm, P. (2012). Epidemiology of musculoskeletal injury in the tennis player. British Journal of Sports Medicine, 52, 129-135.

Bahr, R. \& Krosshaug, T. (2005). Understanding injury mechanisms: a key component of preventing injuries in sport. British Journal of Sports Medicine, 39, 324-329.

Chard, M. D. \& Lachman, S. M. (1987). Racquet sports-patterns of injury presenting to a sports clinic. British Journal of Sports Medicine, 21(4), 150-153.

DiFiori, J., Benjamin, H., Brenner, J., Gregory, A., Jayanthi, N., Landry, G., \& Luke, A. (2014). Overuse injuries and burnout in youth sports: a position statement from the American Medical Society for Sports Medicine. Clinical Journal of Sport Medicine, 24(1), 3-20.

Duco, L. (2005). Injuries among elite and non-elite Filipino gymnasts. Unpublished undergraduate thesis), Quezon City, Philippines: University of the Philippines Diliman.

Hellstrom, M., Jacobsson, B., Sward, L. \& Peterson, L. (1990). Radiologic abnormalities of the thoracolumbar spine in athletes. Acta Radiologica, 31, 127-132.

Hjelm, N., Werner, S. \& Renstrom, P. (2010). Injury profile in junior tennis players: a prospective two-year study. Knee Surgery, Sports Traumatology, Arthroscopy, 18, 845-850.

Hootman, J., Dick, R. \& Agel, J. (2007). Epidemiology of collegiate injuries for 15 sports: summary and recommendation for injury prevention initiatives. Journal of Athletic Training, 42(2), 311-319.

Ireland, M.L. \& Hutchinson, M.R. (1995). Upper extremity injuries in young athletes. Clinical Journal of Sport Medicine, 14, 533-571.

Kibler, W.B. \& Safran, M.R. (2005). Tennis injuries. Medicine and Sports Science, 48, 120-137.

Lanese, R., Strauss, R., Leizman, D. \& Rotondi, A.M. (1990). Injury and disability in matched men's and women's intercollegiate sports. American Journal of Public Health, 80, 1459-1462.

Pluim, B., Staal, J. B., Windler, G. E. \& Jayanthi, N. (2006). Tennis injuries: occurrence, aetiology and prevention. British Journal of Sports Medicine, 40, 415-423.

Rechel, J., Yard, E. \& Comstock, D. (2008). An Epidemiologic Comparison of High School Sports Injuries Sustained in Practice and Competition. Journal of Athletic Training, 43(2), 197-204.

Reid, M. \& Schneiker, K. (2007). Strength and conditioning in tennis: current research and practice. Journal of Science and Medicine in Sport, 11(3), 248-256.

Renstrom, P. (1995). Knee pain in tennis players. Clinical Journal of Sport Medicine, 14, 163-175.

Reyes, M. (2005). Injuries common to recreational badminton players. Unpublished undergraduate thesis, Quezon City, Philippines: University of the Philippines Diliman.

Safran, M.R., Zachazewski, J.E., Benedetti, R.S., Bartolozzi III, A.R. \& Mendelbaum, R. (1999). Lateral ankle sprains: a comprehensive review part 2 - treatment and rehabilitation with an emphasis on the athlete. Medicine and Sports Science, 31(7), S438-S447. 